\title{
Bypass grafting to the right coronary artery with and without endarterectomy: patency at one year
}

\author{
P H KAY, N BROOKS, P MAGEE, M F STURRIDGE, R K WALESBY, \\ J E C WRIGHT
}

From the London Chest Hospital, London

SUMMARY Between January 1979 and December 1981, 142 patients undergoing surgery to the right coronary artery agreed to have repeat coronary arteriography one year later. Thirty patients underwent combined endarterectomy and bypass grafting to the right coronary artery. The patency of these grafts was compared with that of grafts in 69 patients undergoing direct grafting to the right coronary artery and in $\mathbf{4 3}$ with grafting to the posterior descending coronary artery. There were two hospital deaths and one late death. No patients developed new inferior $Q$ waves on the electrocardiogram. Repeat coronary arteriography at one year showed that $21(72 \%)$ of the 29 grafts were patent after combined endarterectomy and bypass grafting to the right coronary artery. Sixty three $(94 \%)$ grafts to the right coronary artery and $40(93 \%)$ grafts to the posterior descending coronary artery were patent at one year. Direct grafts to the right coronary artery or its posterior descending branch had a significantly higher patency rate at one year than grafts to the endarterectomised right coronary artery.

Graft patency after the combined procedure correlated with the extent of atherosclerosis in the posterior descending coronary artery. It was not influenced by treatment with platelet antagonists. Endarterectomy of the right coronary artery was most successful when it allowed a single graft to perfuse both the large posterior descending and left ventricular branches.

Coronary artery bypass grafting is now the treatment of choice for symptomatic patients with severe left main stem disease. ${ }^{12}$ Patients with chronic stable angina and minimal impairment of left ventricular function with either triple vessel disease ${ }^{34}$ or double vessel disease involving the proximal third of the left anterior descending coronary artery ${ }^{4}$ may also have an improved survival after coronary artery surgery. Moreover, coronary artery bypass grafting provides excellent pain relief for those patients with less widespread atheroma whose angina proves refractory to medical treatment. ${ }^{5}$

Isolated coronary endarterectomy was first described in $1957 . .^{6}$ The later combination of endarterectomy and coronary artery bypass grafting has widened the scope of myocardial revascularisation in patients with diffuse coronary disease. ${ }^{7-14}$ This technique is suitable particularly for the right

Requests for reprints to Mr P H Kay, FRCS, Brompton Hospital, Fulham Road, London SW3 6HP.

Accepted for publication 9 July 1985 coronary artery which is straighter than the left and surgically accessible to the level of its posterior descending branch.

There have been several retrospective reports of graft patency after combined endarterectomy and coronary artery bypass grafting to the right coronary artery. ${ }^{7-111314}$ We present a prospective study of 30 patients undergoing combined endarterectomy and bypass grafting to the right coronary artery. The results are compared with those of similar groups of patients undergoing grafts to the right coronary artery or its posterior descending branch.

\section{Patients and methods}

From January 1979 to December 1981 approximately 750 patients underwent isolated coronary artery surgery at the London Chest Hospital. All patients aged less than 70 years and who were able to tolerate aspirin were approached and asked to take part in a prospective trial entailing elective repeat coronary arteriography at one year. We report the results in the 142 patients undergoing surgery to the 
Table 1 Preoperative clinical characteristics

\begin{tabular}{llcl}
\hline & $R C A-V G(n=69)$ & $P D A-V G(n=43)$ & $E-R C A-V G(n=30)$ \\
\hline Mean age & 55 & 52 & 55 \\
Angina grade (mode) & 3 & 3 & 3 \\
Smoker & $38(55 \%)$ & $25(58 \%)$ & $14(47 \%)$ \\
Diabetes & $4(6 \%)$ & $5(12 \%)$ & $8(13 \%)$ \\
Hypertension & $10(15 \%)$ & $6(14 \%)$ & $12(27 \%)$ \\
Hyperlipidaemia & $2(3 \%)$ & $7(16 \%)$ & $20(67 \%)$ \\
Myocardial infarction & $43(62 \%)$ & $27(63 \%)$ & $22(73 \%)$ \\
LV asynergy (angiography) & $53(77 \%)$ & $31(72 \%)$ & \\
\hline
\end{tabular}

LV, left ventricular; RCA-VG, right coronary artery vein graft; PDA-VG, posterior descending coronary artery vein graft; E-RCA-VG, endarterectomy and RCA-VG.

$\star E-R C A-V G$ vs RCA-VG, $p<0.05 ; \mathrm{E}-\mathrm{RCA}-V G$ vs PDA-VG, $\mathrm{p}<0.05$.

right coronary artery who fulfilled these criteria. In all cases the right coronary artery was angiographically dominant and gave rise to the posterior descending artery.

The mean age of the patients was 54 years (range 28-68) and the male to female ratio was 8:1. All patients presented with angina (mode of grade III on the New York Heart Association Classification). Their preoperative clinical characteristics are shown in Table 1 . Only one clinical variable, the incidence of hyperlipidaemia, was significantly more common in the group of patients undergoing combined endarterectomy and bypass grafting to the right coronary artery $(p<0.05)$.

\section{OPERATIVE DETAILS}

The operative technique was left to the discretion of the individual surgeon. Cardiopulmonary bypass was established between the right atrium and the ascending aorta. In 124 patients the distal anastomoses were constructed during short periods of elective ventricular fibrillation with the aorta cross clamped, the nasopharyngeal temperature having drifted to $32^{\circ} \mathrm{C}$. In 18 patients the distal anastomoses were constructed during a single period of cold cardioplegic arrest with the oesophageal temperature at $28^{\circ} \mathrm{C}$. The number of grafts of greatest frequency was three per patient (range 2-5). The choice of surgical procedure for grafting the right coronary artery was determined by its angiographic appearance. In all cases the anastomosis was constructed using a continuous suture of $6 / 0$ Prolene.

Coronary artery bypass graft to the right coronary artery $(R C A-V G)$-Sixty nine patients with proximal disease in the right coronary artery and a distal vessel of good angiographic appearance underwent direct saphenous vein grafting to the right coronary artery.

Coronary artery bypass graft to the posterior descending coronary artery (PDA-VG)-Forty three patients with widespread atheroma of the main right coronary artery but a disease free posterior descending branch greater than $1 \mathrm{~mm}$ in diameter underwent direct grafting into the posterior descending artery.

Combined endarterectomy and bypass graft to the right coronary artery $(E-R C A-V G)$-Thirty patients underwent combined endarterectomy and bypass grafting to the right coronary artery. This included nine patients with occlusive disease at the crux in whom a successful endarterectomy allowed a single graft to perfuse both posterior descending and left ventricular branches. In a further nine patients the decision to perform an endarterectomy was made after the right coronary artery had been opened. In twelve patients the posterior descending artery was too diffusely diseased to be grafted.

\section{TECHNIQUE OF ENDARTERECTOMY}

In every instance a mechanical endarterectomy was performed, though the technique varied with the individual operator. The acute margin of the heart was retracted to expose the distal right coronary artery. A $1 \mathrm{~cm}$ incision was made $1 \mathrm{~cm}$ proximal to the origin of the posterior descending branch and the correct endarterectomy plane in the media was established. The atheromatous core was first mobilised proximally by means of a combination of mechanical traction with De Bakey forceps and blunt dissection with a Watson-Cheyne dissector. Usually when $2 \mathrm{~cm}$ of the core had been mobilised proximally it was divided cleanly with scissors. A similar technique of traction with the forceps and dissection with the dissector was used to mobilise the core distally and free the posterior descending and left ventricular branches. The core was then withdrawn by exerting traction on it with forceps and counter traction on the epicardium with a second pair of forceps. The patency of the distal vessels was confirmed by the passage of a $1 \mathrm{~mm}$ probe. In one case the core broke and was retrieved by a second arteriotomy in the posterior descending artery. In this case the graft was anastomosed to the posterior descending artery and the right coronary artery was closed with a vein 
Table 2 Hospital mortality and morbidity

\begin{tabular}{lllll}
\hline & $\begin{array}{l}R C A-V G \\
(n=69)\end{array}$ & $\begin{array}{l}P D A-V G \\
(n=43)\end{array}$ & $\begin{array}{l}E-R C A-V G \\
(n=30)\end{array}$ & $\begin{array}{l}\text { Total } \\
(n=142)\end{array}$ \\
\hline $\begin{array}{l}\text { No of grafts per patient (mode and range) } \\
\text { Mortality }\end{array}$ & $\begin{array}{l}3(2-5) \\
\text { New inferior Q waves }\end{array}$ & $3(2-5)$ & $3(2-4)$ & $3(2-5)$ \\
\hline
\end{tabular}

RCA-VG, right coronary artery vein graft; PDA-VG, posterior descending artery vein graft; E-RCA-VG, endarterectomy and RCA-VG.

patch.

In addition the 142 patients received a total of 306 grafts to the left coronary system. Endarterectomy was not performed on any branches of the left coronary artery.

All patients were given warfarin anticoagulation for three months from the second postoperative day to maintain a prothrombin time of between 24 and 30 seconds. In addition, the patients were randomised according to the double blind protocol of one of the authors (NB) to receive either aspirin $990 \mathrm{mg}$ and dipyridamole $225 \mathrm{mg}$ daily or placebo for twelve months from the first postoperative day. Thirty two $(48 \%)$ patients received platelet antagonists after right coronary artery grafting, $23(53 \%)$ after grafts to the posterior descending artery, and $16(53 \%)$ after combined endarterectomy and bypass grafting to the right coronary artery.

\section{FOLLOW UP}

All surviving patients were admitted to the London Chest Hospital for elective recatheterisation a mean of 12 months (range 11-14) after the operation.

\section{STATISTICAL ANALYSIS}

Fisher's exact test was used for statistical analysis, the level of significance being set at $\mathbf{p}<0.05$.

\section{Results}

HOSPITAL MORTALITY AND MORBIDITY

Two patients died within 30 days of operation, one after a graft to the right coronary artery (mortality after RCA-VG 1.4\%) and the second after a combined endarterectomy and bypass grafting to the right coronary artery (mortality after E-RCA-VG
$3.3 \%)$. Although seven $(5 \%)$ of the 140 operative survivors developed new $Q$ waves on the electrocardiogram indicating perioperative myocardial infarction, none of these was in the inferior position. The distribution of these events is summarised in Table 2.

\section{LATE RESULTS}

There was one late death from a myocardial infarction six months after triple coronary artery bypass grafting which included the right coronary artery. Thus, the one year survival of the total group of 142 patients was $98 \%$.

A second patient who had undergone right coronary artery grafting had a late anterior myocardial infarction associated with occlusion of the anterior descending graft.

Fifteen $(11 \%)$ patients complained of residual angina (nine grade I, four grade II, and two grade III, New York Heart Association classification). The two patients with more severe angina have undergone repeat myocardial revascularisation. These late results are summarised in Table 3.

\section{GRAFT PATENCY}

Elective coronary arteriography was performed in the 139 surviving patients a mean of 12 months after operation. Sixty three (94\%) of the 67 grafts to the right coronary artery and $40(93 \%)$ of the 43 grafts to the posterior descending artery were patent, as were twenty one $(72 \%)$ of the 29 grafts in patients who had undergone combined endarterectomy and bypass grafting to the right coronary artery (patency RCA-VG vs E-RCA-VG, $p<0.01$; patency PDAVG vs E-RCA-VG, $\mathrm{p}<0.01$ ).

Table 3 Results at one year

\begin{tabular}{lllll}
\hline & $\begin{array}{l}R C A-V G \\
(n=68)\end{array}$ & $\begin{array}{l}P D A-V G \\
(n=43)\end{array}$ & $\begin{array}{l}E-R C A-V G \\
(n=29)\end{array}$ & $\begin{array}{l}\text { Total } \\
(n=140)\end{array}$ \\
\hline Late mortality & $1(1.5 \%)$ & Nil & Nil & $\begin{array}{l}1(0.7 \%) \\
2(1.4 \%) \\
\text { Late myocardial infarction }\end{array}$ \\
Recurrent angina & $2(2.9 \%)$ & Nil & Nil & $15(11 \%)$ \\
\hline
\end{tabular}

RCA-VG, right coronary artery vein graft; PDA-VG, posterior descending artery vein graft; E-RCA-VG, endarterectomy and RCA-VG. 
Table 4 Relation between graft occlusion and infarction or recurrent angina

\begin{tabular}{|c|c|c|c|c|c|c|}
\hline \multirow[t]{3}{*}{ Graft } & \multicolumn{3}{|c|}{ Myocardial infarction } & \multicolumn{3}{|c|}{ Recurrent angina } \\
\hline & \multicolumn{3}{|c|}{ Graft occlusion } & \multicolumn{3}{|c|}{ Graft occlusion/stenosis } \\
\hline & Right & Left & $R i g h t+$ left & Right & Left & Right + left \\
\hline $\begin{array}{l}\text { RCA-VG } \\
\text { PDA-VG } \\
\text { E-RCA-VG }\end{array}$ & $\begin{array}{l}0 \\
0 \\
0\end{array}$ & $\begin{array}{l}4 \\
2 \\
2\end{array}$ & $\begin{array}{l}0 \\
0 \\
0\end{array}$ & $\begin{array}{l}1 \\
0 \\
5\end{array}$ & $\begin{array}{l}3 \\
2 \\
1\end{array}$ & $\begin{array}{l}1 \\
1 \\
1\end{array}$ \\
\hline
\end{tabular}

^Excludes one patient who died after a late myocardial infarction.

RCA-VG, right coronary artery vein graft; PDA-VG, posterior descending artery vein graft; E-RCA-VG, endarterectomy and RCA-VG.

Thirty $(94 \%)$ of grafts to the right coronary artery in the thirty two patients taking aspirin and dipyridamole were patent at one year, compared with $33(94 \%)$ in the 35 control patients. Grafts to the posterior descending artery were patent in $21(91 \%)$ of the 23 patients on antiplatelet treatment and in 19 $(95 \%)$ of the 20 patients who were not on platelet antagonists. Twelve (75\%) of the grafts to the endarterectomised right coronary artery were patent in the 16 patients taking aspirin and dipyridamole, compared with nine $(69 \%)$ in the 13 control patients.

Two hundred and sixty four $(88 \%)$ of the 301 grafts anastomosed to the left coronary circulation were patent at one year in surviving patients. The results were similar in each of the three groups. There was no correlation between occlusion of grafts to the right coronary artery and those to the left coronary system.

Forty one $(29 \%)$ of the 139 surviving patients had one or more occluded grafts. They included the eight surviving patients who had perioperative or late myocardial infarctions and 13 of the 15 patients continuing to experience angina. The other two cases of late angina had evidence of graft stenosis at the coronary anastomosis. There were no other cases of graft stenosis at the coronary anastomosis.

Fifteen patients had occluded grafts to the right coronary artery. In no case did this lead to the development of new inferior $Q$ waves. All perioperative or late myocardial infarctions were associated with occlusion of a graft to the left coronary system. Nine $(60 \%)$ of the 15 patients with occluded right coro-

Table 5 Results of endarterectomy and right coronary artery vein grafting

\begin{tabular}{lll}
\hline & $\begin{array}{l}\text { Large }(>1 \mathrm{~mm}) \\
P D A(n=18)\end{array}$ & $\begin{array}{l}P D A \text { ungraftable } \\
(n=12)\end{array}$ \\
\hline Hospital mortality & 0 & $1(8 \%)$ \\
Late mortality & 0 & 0 \\
Late infarction & 0 & 0 \\
Recurrent angina & $2(11 \%)$ & $5(45 \%)$ \\
Graft patency & $16(89 \%)$ & $5(45 \%)$ \\
\hline
\end{tabular}

PDA, posterior descending artery. nary artery grafts continued to experience angina; these were predominantly in the group who had undergone endarterectomy. The relation between graft occlusion/stenosis and myocardial infarction and recurrent angina is shown in Table 4.

ANALYSIS OF ENDARTERECTOMY RESULTS

Patients undergoing combined endarterectomy and bypass grafting to the right coronary artery were divided into two subgroups according to suitability of the posterior descending branch for grafting. The results for these two subgroups are outlined in Table 5 . Sixteen $(89 \%)$ of the 18 patients with a large posterior descending artery had patent right coronary artery grafts after combined endarterectomy and bypass grafting. This figure is not significantly different from the $93 \%$ patency rate in patients who had undergone direct grafting to the posterior descending artery. Conversely, in the subgroup of patients in whom the posterior descending artery was unsuitable for grafting five ( $45 \%$ ) grafts were patent and five $(45 \%)$ of the 11 surviving patients continued to experience low grade (New York Heart Association grade I or II) angina.

\section{Discussion}

In this prospective study we attempted to define the best surgical approach to the diseased right coronary artery as assessed by graft patency at one year. Though we studied a selected group of patients, selection was purely in terms of patient compliance rather than clinical variables. Indeed, the preoperative clinical characteristics of our patients were similar to those in another series. ${ }^{12}$

The overall early results, with a $1.4 \%$ hospital mortality and a $5 \%$ incidence of perioperative myocardial infarction, are similar to those reported by other centres. ${ }^{15-17}$ Three hundred and sixty seven $(89 \%)$ of the 411 grafts performed without endarterectomy were patent at a mean of 12 months after the operation. This level of graft patency is higher than that reported by other centres. ${ }^{18-21}$

Two patients had late myocardial infarctions, one of which was fatal, while 15 other patients experi- 
enced residual angina. In each instance there was graft failure (occlusion in 14 cases and stenosis at the coronary anastomosis in two cases) rather than progression of distal disease in the native vessels. Thus, in the presence of complete myocardial revascularisation, recurrence of symptoms in the first year signified graft failure. The converse, however, did not necessarily apply since $20(49 \%)$ patients with graft occlusion were symptom free and had no new ischaemic changes on the electrocardiogram.

This paper confirms that endarterectomy of the right coronary artery can be performed safely with no significant increase in hospital mortality, ${ }^{701213}$ and in this series there was no associated inferior myocardial infarction. The $6.7 \%$ incidence of perioperative infarction was associated only with occlusions of left sided grafts. Thus, unlike Miller $e t$ $a l^{12}$ we did not demonstrate an increased incidence of myocardial damage after endarterectomy. The long term results, however, with seven $(24 \%)$ of the 29 surviving patients continuing to experience angina compared with five $(7 \%)$ of the 68 patients who had undergone direct grafting to the right coronary artery $(p<0.05)$ indicate that this technique may be less beneficial. This result accorded with a significant difference in the patency rate of the right coronary grafts in the group without endarterectomy $(94 \%)$ and the group with endarterectomy $(72 \%)$ $(p<0.01)$. Thus, the overall results of combined endarterectomy and bypass grafting to the right coronary artery appear at first sight to be inferior to those of direct grafting on to the right coronary artery itself.

Patients undergoing combined endarterectomy and bypass grafting to the right coronary artery were composed of two subgroups; those with a large $(>1 \mathrm{~mm})$ disease free posterior descending artery which was suitable for grafting and those in whom the posterior descending artery was unsuitable for grafting either because of its small size or because extensive disease was present. The results of combined endarterectomy and bypass grafting in patients with a graftable posterior descending artery and direct grafting of the posterior descending artery were not significantly different. The $89 \%$ patency rate for the combined procedure in this subgroup compares favourably with that reported in other series. $^{79-111314}$ These good results are balanced by the poor results of endarterectomy in patients with small $(<1 \mathrm{~mm})$ or heavily diseased posterior descending arteries in whom only $45 \%$ grafts were patent at one year (Table 5). Clearly, these subgroups represent extreme ends of a spectrum of disease. Comparison of results from different centres will be greatly influenced by the distribution of these subgroups within a given series.

Information in previous reports of combined endarterectomy and bypass grafting has always been gathered retrospectively. ${ }^{79-14}$ The aim of endarterectomy has been loosely stated as being to increase the scope of myocardial revascularisation, though the size of the distal vessels has not been given. Both Miller $e t a^{12}$ and Keon ${ }^{22}$ suggest that a direct graft to the distal vessel is preferable to endarterectomy, though neither supports this with data on graft patency. Keon sets a lower limit of 1.5 $\mathrm{mm}$ on the size of the posterior descending artery which is suitable for grafting. ${ }^{22}$ We believe that our data suggest that this figure can now be reduced to $1.0 \mathrm{~mm}$.

Our results did not show a beneficial effect of platelet inhibiting drugs on graft patency in any of the three operative groups. This was particularly surprising in the endarterectomy group and was in direct contrast to Chesebro et al's conclusions. ${ }^{19}$ There are several differences, however, between the two trials. In the American series dipyridamole therapy was started before operation and aspirin was added on the day of operation. In our series platelet inhibiting drugs were started after removal of the chest drains on the first postoperative day. This treatment was supplemented with warfarin anticoagulation for three months. The patency of grafts to the non-endarterectomised right coronary artery or its posterior descending branch was $95 \%$ in our placebo group. This was similar to the $97 \%$ patency in Chesebro's treated group and significantly higher than the $80 \%$ patency of his control group. Thus, it is probable that the beneficial effects of aspirin and dipyridamole were masked by the three month period of anticoagulation.

The dilemma of whether it is better to perform an endarterectomy on a large (3-4 $\mathrm{mm}$ ) right coronary artery before saphenous vein grafting or to anastomose the graft directly to a posterior descending artery $1.0-1.5 \mathrm{~mm}$ in diameter remains unresolved. The position is further complicated when there are two large disconnected distal branches of the right coronary artery, as there were in eleven patients in the series. Nine patients were treated by combined endarterectomy and bypass grafting which allowed both branches to be perfused by a single graft. The other two patients were treated by individual grafts to the posterior descending artery and distal left ventricular branch. All these grafts were patent at re-examination. Thus, the tendency to perform combined endarterectomy and bypass grafting will remain idiosyncratic.

\section{Conclusions}

We have now adopted the following surgical ap- 
proach on the basis of both preoperative assessment and direct inspection of the right coronary artery at operation: (a) Our first choice of procedure is a direct graft to the main coronary artery. (b) If the right coronary artery is unsuitable for grafting attention is turned to its posterior descending branch. A graft to this artery gives equally good results at one year. (c) Occlusive disease of the crux of the right coronary artery with a large posterior descending branch may be satisfactorily treated by combined endarterectomy and bypass grafting. This approach results in a similar patency rate to that of direct grafts to the posterior descending artery and has the advantage that a single graft perfuses both posterior descending and left ventricular branches. If the posterior descending artery is unsuitable for grafting the results of combined endarterectomy and bypass grafting to the right coronary artery are poor with a low graft patency and a high frequency of recurrent angina.

\section{References}

1 Loop FD, Lytle BW, Cosgrove DM, et al. Atherosclerosis of the left main coronary artery. Five year results of surgical treatment. Am $\mathcal{f}$ Cardiol 1979; 44: 195-201.

2 Takaro T, Peduzzi P, Detre KM, et al. Survival in subgroups of patients with left main coronary artery disease. Veterans Administration Co-operative Study of surgery for coronary arterial occlusive disease. Circulation 1982; 66: 14-22.

3 Hammermeister KE, Derouen TA, Dodge HT. Comparison of survival of medically and surgically treated coronary disease patients in Seattle Heartwatch: a nonrandomised study. Circulation 1982; 65 (suppl II): 53-9.

4 Varnauskas E, Olsson SB, Carlström E, et al. Longterm results of prospective randomised study of coronary artery by-pass surgery in stable angina pectoris. Final report of European Coronary Surgery Study Group. Lancet 1982; ii: 1173-80.

5 Loop FD, Cosgrove DM, Lytle BW, et al. An 11-year evolution of coronary arterial surgery (1967-1978). Ann Surg 1979; 190: 444-51.

6 Bailey CP, May A, Lemmon WM. Survival after coronary endarterectomy in man. $\mathcal{F} A M A$ 1957; 164: 641-6.

7 Cheanvechai C, Groves LK, Reyes EA, Shirey EK, Sones FM Jr. Manual coronary endarterectomy. Clinical experience in 315 patients. $\mathcal{f}$ Thorac Cardiovasc Surg 1975; 70: 524-8.

8 Dumanian AV. Endarterectomy of the branches of the left coronary artery in combination with aorta-tocoronary artery reversed saphenous vein graft. $f$ Cardiovasc Surg (Torino) 1974; 15: 154-7.

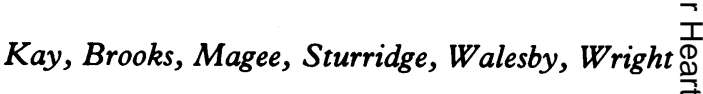

9 Groves LK, Loop FD, Silver GM. Endarterectomy as $\stackrel{.}{.}$ a supplement to coronary artery-saphenous vein by- $\vec{F}$

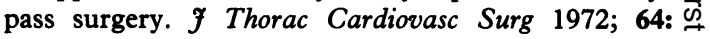
514-22.

10 Hochberg MS, Merrill WH, Michaelis LL, McIntosh $\frac{\bar{C}}{\mathrm{C}}$ CL. Results of combined coronary endarterectomy and $\bar{S}$ coronary by-pass for diffuse coronary artery disease. $\mathcal{F} \stackrel{\nabla}{\Phi}$ Thorac Cardiovasc Surg 1978; 75: 38-46.

11 Keon WJ, Akyurekli Y, Bedard P, Brais MP, Goldstein के W, Beanlands DS. Coronary endarterectomy; an ad- $\overrightarrow{0}$ junct to coronary artery by-pass grafting. Surgery 1979; 86: 859-67.

12 Miller DC, Stinson EB, Oyer PE, et al. Long-term clinical assessment of the efficacy of adjunctive coronary endarterectomy. $\mathcal{F}$ Thorac Cardiovasc Surg 1981; 81: 21-9.

13 Wallsh E, Franzone AJ, Clauss RH, Armellini C, Steichen F, Stertzer SH. Manual coronary endarterectomy with saphenous by-pass: experience with 263 patients. Ann Thorac Surg 1981; 32: 451-5.

14 Yacoub MH. Fawzy E, Anyanwu H, Towers M. Combined gas endarterectomy and coronary artery by-pass graft. Circulation 1975; 51 and 52 (suppl 1): 182-7.

15 Kennedy JW, Kaiser GC, Fisher LD, et al. Multivariate discriminant analysis of the clinical and angio- $\mathbb{D}$ graphic predictors of operative mortality from the Collaborative Study in Coronary Artery Surgery (CASS). F Thorac Cardiovasc Surg 1980; 80: 876-87.

16 Kouchoukos NT, Oberman A, Kirklin JW, et al. Coronary by-pass surgery: analysis of factors affecting hospital mortality. Circulation 1980; 62 (suppl I): 84-9.

17 Loop FD, Sheldon WC, Lytle BW, Cosgrove DM III, Proudfit WL. The efficacy of coronary artery surgery. Am Heart f 1981; 101: 86-96.

18 Campeau L, Lesperance J, Hermann J, Corbara F, $\overrightarrow{\bar{O}}$ Grondin CM, Bourassa MG. Loss of the improvement of angina between one and seven years after aortocoronary by-pass surgery. Circulation 1979; 60 (suppl I): 1-5.

19 Chesebro JH, Clements IP, Fuster V, et al. A plateletinhibitor-drug trial in coronary artery bypass operations. Benefit of perioperative dipyridamole and aspirin therapy on early post-operative vein graft patency. $N$ Engl f Med 1982; 307: 73-8.

20 Hamby RI, Aintablian A, Handler M, et al. Aortocoronary saphenous vein by-pass grafts. Long-term patency, morphology and blood flow in patients with 윽 patent grafts early after surgery. Circulation 1979; 60: 901-9.

21 Sharma GVRK, Khuri SF, Folland ED, Barsamian EM, Parisi AF. Prognosis for aorto-coronary graft pa- $\sigma$ tency. A comparison of pre-operative and intra- N operative assessments. $\mathcal{F}$ Thorac Cardiovasc Surg 1983; N 85: 570-6.

22 Keon WJ. Manual coronary endarterectomy and re- $\underset{<}{ }$ vascularisation: improving techniques and results. $A n n$ 응 Thorac Surg 1981; 32: 427-8. 